\title{
Socio-cultural Constraints and Women's Decision-making Power Regarding Reproductive Behaviour
}

\author{
Syed MubashiR Ali and MeHBOOB SultaN
}

\section{INTRODUCTION}

In a previous study [Ali, Siyal and Sultan (1995)], we observed a big gap between behaviour and desires. Only 35 percent women had the number of children that they had desired. Whereas, a very large number of women had more children than their stated ideal number of children. The same data set also showed that a majority of women (54 percent) either wanted to stop having children or wanted to wait at least two years before having another child [Ali and Rukanuddin (1992)]. In practice, all of these women were not protected; instead only 12 percent were practising contraception [Shah and Ali (1992)]. An argument was put forward that, had these women been empowered to decide about the number of children to be born, the scenario would have been different and small family size norms would have prevailed.

However, the finding of that study revealed that generally, the women who were considered to be empowered were actually constrained to exercise fertility control behaviour. It was hypothesised that socio-cultural influences including those of husbands, in-laws and other family members impelled women to become incapacitated.

In the present study, an effort has been made to investigate and identify factors that influence women's decision making about reproductive behaviour. Furthermore, an attempt to measure the extent of these influences has been made.

\section{METHODOLOGY AND VARIABLES}

The technique of Multiple Regression analysis is used to test the effect of each independent variable on a dependent variable. The results are based on eleven

Syed Mubashir Ali and Mehboob Sultan are Senior Research Demographer at Pakistan Institute of Development Economics and Senior Fellow at National Institute of Population Studies, Islamabad, respectively.

Authors' Note: Thanks are due to Mr Masood Ashfaque (Systems Analyst) for the assistance in data analysis. 
equations. The first equation is based on all currently married women who have given birth to at least one child in the last five years preceding the survey. Equation 2 and 3 are the breakdown of the women in Equation 1 by Family Type i.e., nuclear and joint family. It is hypothesised that women living in nuclear families are relatively free in decision-making and actions; as cultural pressures and influences particularly of in-laws are less pronounced.

In Pakistan, many studies, [Soomro and Ali (1984); Shah and Ali (1992); Bhatti and Hakim (1998)] have cited husband's opposition as one of the major reason for not using contraceptives. However, educated husbands are likely to behave differently from uneducated ones. Thus husbands' influence on wives may also vary from household to household. The sample of women on which Equation 2 and 3 are based, is further classified into those whose husbands are either illiterate or less than 'primary passed' and those whose husbands are educated. Here all those women whose husbands are illiterate or less than 'primary passed' are categorised as uneducated whereas, those women whose husbands have acquired primary education or more are categorised as educated. The rationale for including less than 'primary passed' into the uneducated category is because of the demographic behaviour of the uneducated which does not differ much from that of the women who have done less than primary level.

A more refined breakdown of the sample is obtained when we divide women living in nuclear and joint families further into those whose husbands are in white collar and blue collar jobs. It is hypothesised that circumstances and position of a woman vary in households where husbands are engaged in white collar jobs than those households where husbands are in blue collar jobs. Thus women may behave differently in various types of households.

The dependent variable is Children Ever Born (CEB). Whereas, most of the independent variables ${ }^{1}$ used in the analysis are the same as were used in the previous study, the independent variable 'female head of household' was dropped from the analysis and 'contraceptive use' as a variable was added instead. The variable "female head of household" was dropped because of two reasons: firstly, because it did not show any impact on CEB in the previous analysis and secondly because of the small number of females (95) as head of household in the sample. This sample when further divided into four categories did not yield sufficient observations needed in a regression equation, and hence could cause wrong interpretation of the results.

The variable 'ever use of contraceptive' when reported in affirmative by women indicated that all those who had ever used contraceptives had had the grit and authority to decide about its use in order to choose a specific number of children, and hence were termed as empowered. This variable is used as dummy variable where the value ' 1 ' is given to all those women who have reported ever use of contraception and ' 0 ' to those who have never used it.

${ }^{1}$ Please see [Ali, Siyal, and Sultan (1995)] for details about some of the independent variables. 
The empowerment of women in this analysis was measured by another set of questions; that is "at the time you became pregnant with (name of the child) did you want to become pregnant 'then'? Did you want to wait until 'later' or did you want ' no more' children at all?" The response to these questions endorses women's choice and determination. The empowerment status of a women was determined in such a way that all those women who wanted the baby at the time of their pregnancy were considered to be empowered and were assigned code ' 1 '. The code ' 0 ' was assigned to those who gave response to IInd and IIIrd category of questions.

A woman who could go to a health clinic or a hospital alone was considered to have freedom of mobility and hence was socially independent. Such a woman may be considered empowered, implying the likelihood of her participation in decision- making. This variable is used in the regression equation in a dummy style where all those who responded in affirmative to the question on freedom of mobility are assigned ' 1 ' and ' 0 ' is assigned to all those who responded in the negative.

'Female education' and 'female labour force participation' are the two other variables used here in the analysis. Both these variables depict the status of women. These variables bring autonomy to women. By acquiring education, women are exposed to the outside world, thus improving their perspectives and attitudes. Economic emancipation comes from earning money, allowing them to take control of their lives. In other words, female education and employment provides confidence which in turn allows women to take decisions about the number of children to be produced. In the analysis, female education is used as a continuous variable whereas all those women currently doing any job are assigned code ' 1 ' and those not doing any job are assigned code ' 0 '.

Another independent variable is women's response to ideal family size. In response to the question on ideal family size, some women gave numeric answers whereas many termed the question as interference in God's affairs. All those who gave numeric responses are considered to have had the courage to decide about the number of children, and may be said to have empowerment of decision-making. Whereas, all those who gave non-numeric responses are 'fatalists'. In other words, these women may be said to have resigned their power and tend to accept whatever is in their 'fate'. This variable is used as dummy variable in the regression equations where value ' 1 ' is given to all those women who gave numeric responses, otherwise they are assigned value ' 0 '.

The question, "have you and your husband ever discussed the number of children you would like to have"? when answered in the affirmative, reflects women's worth and status in a decision as vital as the number of children to be produced. Sharing decision-making with their husbands clearly points to the fact that such women enjoy a degree of empowerment. All those women who responded in affirmative are given value ' 1 ', otherwise they are assigned value ' 0 '. 


\section{RESULTS}

The regression results pertaining to 11 equations are presented in Table 1 . It may be pertinent to mention some of the limitations of this exercise right in the beginning.

The present study is based on the data of the 1990-91 PDH Survey. The survey collected information regarding demographic and health issues, and although no specific information on women's empowerment was collected in the survey, efforts were made to include those variables in the paper which reflect women's empowerment and autonomy in decision-making. It may also be noted that there is a discrepancy between the time reference of the explanatory variables and the phenomenon to be explained. Children Ever Born, which is an outcome of lifetime phenomena, may not be adequately explained by the regression exercise based on the cross-sectional nature of the data.

In an exercise to avoid multicollinearity among the explanatory variables, a correlation matrix was produced. The correlation coefficients of all the variables used in this exercise were not found to be high enough to produce any collinearity problem.

A highly significant positive association between the variables 'ever use of contraceptives' and 'CEB' is found in all the equations. Surprisingly, neither the significance level nor the direction of the slope changed across various groups of women. Earlier studies based on Pakistani data have arrived at similar results [DeTray (1976); Irfan and Farooq (1983) and Ali, Siyal and Sultan (1993)]. It is argued that in countries like Pakistan where the contraceptive prevalence is low, it is the high parity women who engage in contraceptive practice [Shah and Ali (1992) and Sathar and Kazi (1997)].

In Pakistan, generally female labour force participation is low. Nevertheless, most of these women are engaged in low paid jobs. Moreover, the majority enters the labour force after marriage [Ahmed and Ali (1992)]. Most probably the increased number of children strains an already meager family income which compels women to enter the labour market. The income earned by these women is infact used in meeting the family's requirements instead of being used on her own welfare that may promote her confidence in decision-making. Infact, relationship of this variable with the dependent variable, is by and large in agreement with the contention stated above. This relationship becomes more conspicuous in nuclear families and particularly where husbands of the women are either uneducated or in blue collar jobs. As a matter of fact, in nuclear families, there is generally no additional working member to supplement the income of the husband other than the wife. Commonly, women in Pakistan do not opt to take up a job unless compelled by financial pressure. The positive and significant relationship here clearly shows that financial pressure due to increased number of children compels women to enter into the labour market. Interestingly, in Equation 10 where women are living in joint families and 
Table 1

Estimated Regression Equations for the Determination of Fertility Behaviour Explained by Women's Empowerment Variables

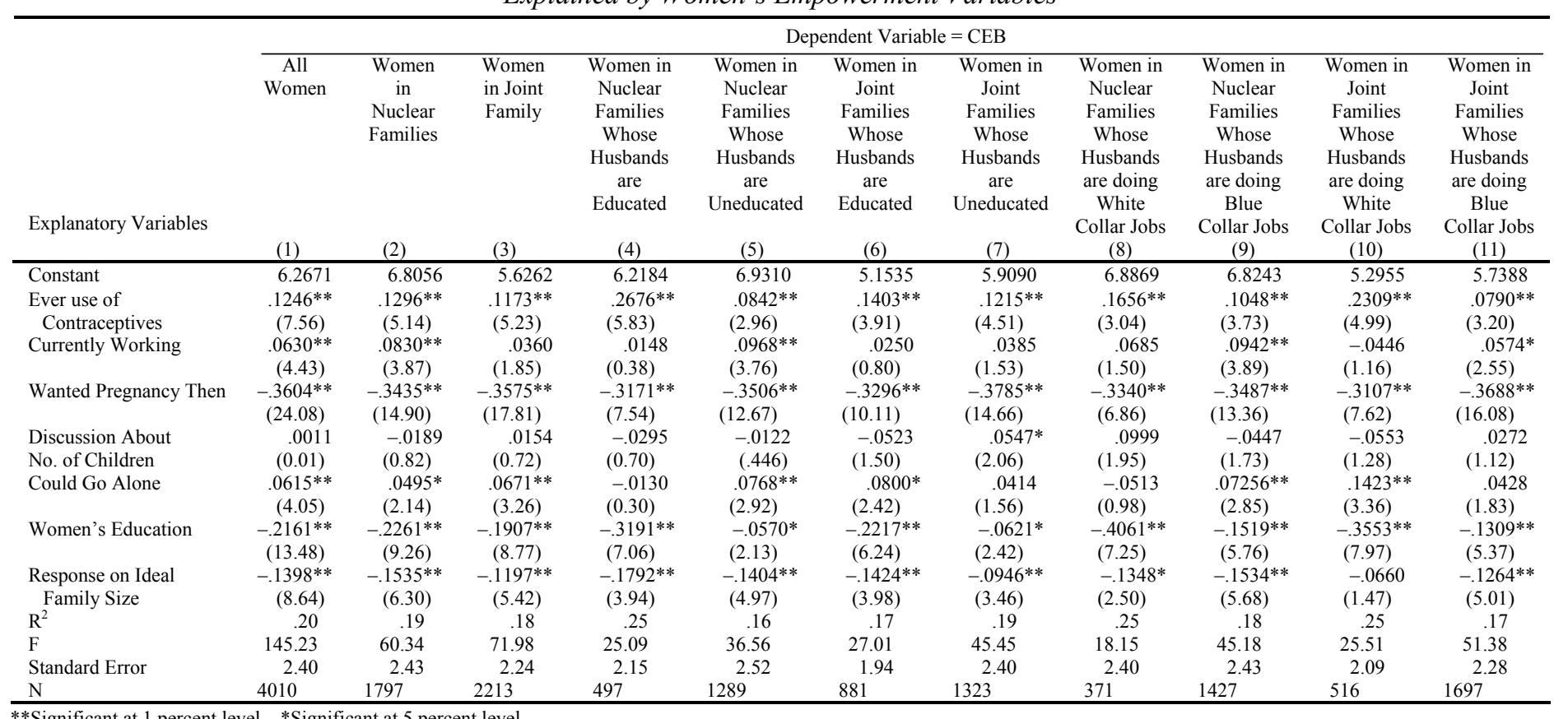

$\begin{array}{lrrr}\mathrm{N} & 4010 & 1797 & 2213 \\ * \text { Significant at } 1 \text { percent level. } & * \text { Significant at } 5 \text { percent level. }\end{array}$ 
their husbands are doing white-collar jobs, current working status of women shows negative relationship with CEB. Although the effect is not significant.

The variable "time wanted pregnancy" used here in the analysis as a proxy for women's empowerment shows a clear and the strongest negative effect on CEB across all 9 Equations. The relationship clearly suggests fewer children ever born for those women who have their babies as planned, irrespective of the setup a woman is residing in. As a matter of fact a unit change in this variable brings a reduction of atleast three-tenth of a child.

It is hypothesised that a setup, where a husband and wife discuss about the number of children they wish to have, is free of coercion and exploitation. In such a situation rational thinking about the number of children is likely to develop. However, the results of the analysis do not indicate any clear cut or significant relationship across these equations except for the one where women reside in joint families and their husbands are uneducated. This is the only equation where this variable yielded not only significant but positive effects as well.

As discussed earlier, a woman who can go out of her house alone is considered socially more independent and autonomous in making a decision to suit herself. However, its effect generally on CEB is positive and significant. Using the data of rural Punjab, [Sathar and Kazi (1997)] also found out a positive and significant relationship between mobility and CEB. They contend that lower caste and poor women are more autonomous in mobility and as such family size is largest among poor women in Pakistan. The two equations where direction of slope is negative pertained to women living in nuclear families whose husbands are either educated or doing white collar jobs. However, the effect is not statistically significant.

Women's education is another variable, the effect of which on CEB is significant and in the right direction across all the equations. The magnitude of effect as shown by beta values is maximum for women whose husbands are in white-collar jobs and particularly for those living in nuclear families.

Yet another variable which generally shows significant effect in the right direction on CEB is the one constructed from the responses on ideal family size. Although its effect in terms of magnitude is not as great as the effect of variables such as 'women's education' and 'wanted pregnancy then', (see Equation 1), yet one thing is clear, that all those women who have the courage to respond in numerics, behave rationally.

\section{SUMMARY AND CONCLUSION}

The aim of the study was to investigate the effects of socio-cultural influences on women empowerment and evaluate its impact on fertility behaviour. The main conclusions drawn from the study are that educational attainment of both husband and wife bring about significant differences in the fertility behaviour irrespective of 
the set up they are residing in. Thus universal education for both male and females, beyond primary level may help change the attitude of the general population. Other variables, which brought significant differences in terms of magnitude, were "wanted pregnancy then" and "response on ideal family size". In other words, those women who had the grit and power to decide about the time of their pregnancy, were infact not influenced by social and cultural values and had the will to exercise their decision-making power about reproductive behaviour. Other variables employed here in the analysis have shown a mixed effect. On the whole, the traditions of large family size in general are so deeply rooted that renders a woman incapacitated.

In order to mitigate such influences campaigns especially through radio and television in the form of dramas and programmes can be very helpful. Such programmes, on the one hand may bring a change in the male attitudes towards females and, on the other will help women realise the importance and benefits of small family size as well as make them aware of their rights that may promote equity in all spheres of life.

\section{REFERENCES}

Ahmed, Tauseef, and S. Mubashir Ali (1992) Characteristics of Households and Respondents. In Pakistan Demographic and Health Survey 1990-91. National Institute of Population Studies. Islamabad/IRD-Macro International Inc., Columbia.

Ali, S. Mubashir, and Razzaque A. Rukanuddin (1992) Family Size Preferences. In Pakistan Demography and Health Survey 1990-91. National Institute of Population Studies, Islamabad/IRD-Macro International Inc. Columbia.

Ali, S. Mubashir, H. B. Siyal, and Mehboob Sultan (1993) How Similar are the Determinants of Mortality and Fertility? The Pakistan Development Review 32:4.

Ali, S. Mubashir, H. B. Siyal, and Mehboob Sultan (1995) Women Empowerment and Reproductive Choice. The Pakistan Development Review 34:4.

Bhatti, Mansoor ul Hassan, and Abdul Hakim (1998) Knowledge and Use of Family Planning Chapter (7). In Pakistan Fertility and Family Planning Survey 1996-97. National Institute of Population Studies, Islamabad. London School of Hygiene and Tropical Medicine, London.

DeTray, Dennis (1976) On the Micro-economics of Family Behaviour in Developing Societies. (Mimeographed.)

Irfan, Mohammad, and G. M. Farooq (1983) An Investigation of Household Reproductive Behaviour in Pakistan. Pakistan Institute of Development Economics, Islamabad. (PLM Report No. 4.)

Sathar, Zaba A., and Shahnaz Kazi (1997) Women's Autonomy, Livelihood and Fertility: A Study of Rural Punjab. Islamabad: Pakistan Institute of Development Economics. 
Shah, Nasra, and S. Mubashir Ali (1992) Knowledge and Use of Family Planning (Chapter 5). In Pakistan Demographic and Health Survey 1990-91. National Institute of Population Studies, Islamabad/IRD-Macro International Inc. Columbia.

Soomro, G. Y., and S. Mubashir Ali (1984) Prevalence of Knowledge and Use of Contraceptive in Pakistan. Studies in Population, Labour Force and Migration. Pakistan Institute of Development Economics, Islamabad. (Project Report No. 3.) 